\title{
SENTIDO DO TRABALHO E FATORES DE QUALIDADE DE VIDA NO TRABALHO: A PERCEPÇÃO DE PROFESSORES BRASILEIROS E CANADENSES ${ }^{i}$
}

\author{
THE MEANING OF WORK AND QUALITY OF WORKING LIFE FACTORS: \\ PERCEPTIONS OF BRAZILIAN AND CANADIAN PROFESSORS \\ EL SENTIDO DEL TRABAJO Y LOS FACTORES DE CALIDAD DE VIDA EN EL \\ TRABAJO: LA PERCEPCIÓN DE PROFESORES BRASILEÑOS Y CANADIENSES
}

\author{
ANA ALICE VILAS BOAS \\ Doutora \\ Universidade Federal de Lavras, Brasil \\ ana.alice@dae.ufla.br \\ ESTELLE M. MORIN \\ Doutora \\ HEC Montréal - Canadá \\ estelle.morin@hec.ca \\ Submetido em : 25/04/2016 \\ Aprovado em : 19/07/2016 \\ Doi : alcance.v23n3.p272-292
}

\begin{abstract}
RESUMO
Este estudo avalia os fatores de qualidade de vida no trabalho (QVT) para os professores que atuam no Brasil e no Canadá e correlaciona-os com o sentido do trabalho. A amostra foi constituída por 274 professores brasileiros e 252 canadenses. Os dados foram coletados por meio de um questionário on-line enviado para 3 universidades públicas de Minas Gerais e 3 universidades do Quebec no primeiro semestre de 2013. O questionário permitiu avaliar os seguintes fatores: finalidade do trabalho, autonomia, oportunidades de desenvolvimento profissional, relação com os colegas, retidão moral, reconhecimento, segurança no trabalho, carga de trabalho e horas trabalhadas por dia e por semana, correlacionando-os com os indicadores de sentido do trabalho e sentido no trabalho. Os professores canadenses encontram mais autonomia, oportunidades de desenvolvimento profissional e reconhecimento em seu ambiente de trabalho do que os brasileiros. Por outro lado, a carga mental e as horas trabalhadas por semana são maiores nas universidades federais de Minas Gerais do que nas universidades do Quebec. Os fatores que descrevem as características do trabalho e das relações de trabalho estão positivamente correlacionados com o sentido do trabalho, enquanto que as cargas de trabalho física e mental estão negativamente relacionadas com o sentido do trabalho.
\end{abstract}

Palavras-chave: QVT; Professores universitários; Sobrecarga de trabalho.

\begin{abstract}
This study assesses quality of working life (QWL) factors among professors working in Brazil and Canada, and correlates them with the meaning of work. The sample consisted of 274 Brazilian professors and 252 Canadian professors. Data were collected through an online questionnaire sent to three public universities in Minas Gerais and three universities of Quebec, in the first half of 2013. Through the questionnaire, the following factors were evaluated: work purpose, autonomy, opportunities for professional development, relationship with colleagues, moral righteousness, recognition, job security, workload and working hours per day and per week; these were then correlated with the "meaning of work" and "meaning at work" indicators. Canadian professors perceived
\end{abstract}


more autonomy, professional development opportunities and recognition in the workplace than Brazilian professors. On the other hand, mental workload and working hours per week were higher in the federal universities of Minas Gerais than in the universities in Québec. Factors describing the characteristics of work and work relations were positively related to the meaning of work, while physical and mental loads were negatively related to the meaning of work.

Key-words: QWL; University professors; Excessive workload.

\section{RESUMEN}

Este estudio evalúa los factores de calidad de vida en el trabajo (QVT) para los profesores que trabajan en Brasil y en Canadá y los correlaciona con el sentido del trabajo. La muestra estaba constituida por 274 profesores brasileños y 252 canadienses. Los datos fueron recogidos por medio de un cuestionario on-line enviado para 3 universidades públicas de Minas Gerais y 3 universidades de Quebec en el primer semestre de 2013. El cuestionario permitió evaluar los siguientes factores: finalidad del trabajo, autonomía, oportunidades de desarrollo profesional, relación con los colegas, rectitud moral, reconocimiento, seguridad en el trabajo, carga de trabajo y horas trabajadas al día y a la semana, correlacionándolos con los indicadores de sentido del trabajo y sentido en el trabajo. Los profesores canadienses encuentran más autonomía, oportunidades de desarrollo profesional y reconocimiento en su ambiente de trabajo que los brasileños. Por otro lado, la carga mental y las horas trabajadas a la semana son mayores en las universidades federales de Minas Gerais que en las universidades de Quebec. Los factores que describen las características del trabajo y de las relaciones de trabalho se correlacionan positivamente con el sentido del trabajo, mientras que las cargas de trabajo física y mental están negativamente correlacionadas con el sentido del trabajo.

Palabras clave: QVT; Profesores universitarios; Sobrecarga de trabajo.

\section{INTRODUÇÃO}

A carreira acadêmica, que já foi vista como segura e como um ambiente de alta posição social, com oportunidades de trabalho satisfatórias e autônomas, atualmente foi alterada drasticamente. $\mathrm{O}$ crescimento do número de alunos e o aumento da ênfase na pesquisa, atrelados à pressão econômica que afeta o nível de demanda de trabalho para professores e outros membros da faculdade, afetam 0 ambiente e a vida dos profissionais do ensino. Todas essas mudanças afetam negativamente a saúde física e mental no domínio acadêmico e como a qualidade de vida no trabalho está intimamente relacionada à saúde física e mental do trabalhador, estes dois construtos devem ser analisados conjuntamente (Morin, 2008 e Vilas Boas e Morin, 2014b).

Gillespie, Walsh, Winefields, Dua e Stough (2001) afirmam que os funcionários das universidades desempenham um papel vital na criação e no desenvolvimento do conhecimento e da inovação, bem como na educação e na formação de toda a sociedade. Assim, é importante que os gestores encontrem maneiras de proteger os professores e os outros membros da equipe dos níveis crescentes de estresse, devido às exigências cada vez maiores. Como exemplo, pode-se destacar a enorme demanda para a publicação em periódicos de alta qualidade para apoiar a carreira do profissional e manter os programas de pós-graduação. Por conseguinte, os professores precisam assumir atividades técnicas, a fim de apresentar projetos de pesquisa, realizar pesquisas e elaborar relatórios para obter material adequado para publicar.

Sobre este assunto, muitos estudos focam o papel "Publicar ou perecer" e esse papel tem aumentado 0 estresse acadêmico para professores e pesquisadores e tem com isso afetado a qualidade de vida no trabalho. É porque, para publicar, os professores precisam trabalhar mais horas e se dedicar às suas próprias pesquisas e às pesquisas de seus alunos de mestrado, doutorado e pós-doutoramento. Todas essas pressões levam 0 estresse relacionado ao trabalho, ao desequilíbrio entre vida e trabalho, tensão mental, física e emocional, e pode causar diferentes problemas de saúde e até mesmo de relacionamento no ambiente de trabalho. Em outras palavras, pode-se dizer que a QVT para os acadêmicos tem sido drasticamente afetada pelas exigências do trabalho, ou mais precisamente pelas demandas de publicação. 
Para ajudar a enfrentar esta realidade, os gestores das universidades devem buscar alternativas para oferecer um ambiente de trabalho saudável e estimulante, o que pode ser entendido como uma melhoria na qualidade de vida dos profissionais. Ketchum e Trist (1992) definiram "qualidade da vida no trabalho" como o estado geral de bem-estar no local de trabalho. Essa qualidade pode ser avaliada por diversos indicadores, tais como bem-estar psicológico, sofrimento psicológico, comprometimento organizacional e equilíbrio trabalho-vida; além dos construtos específicos de sentido do trabalho e sentido no trabalho que se originam da própria forma de organização do trabalho e balizam os demais indicadores de QVT (Vilas Boas \& Morin, 2013, 2013a, 2013b), como também por fatores como objetivo claro de trabalho, autonomia, oportunidades de desenvolvimento profissional, reconhecimento, boas relações com colegas e superiores, percepção de retidão moral no trabalho e nas relações de trabalho, segurança no emprego e carga de trabalho adequada (Vilas Boas \& Morin, 2014).

No entanto, pouco se sabe sobre a QVT nas faculdades ou universidades. Portanto, esse trabalho parte das seguintes questões de pesquisa: Como os fatores de Qualidade de Vida no Trabalho se correlacionam com o sentido do trabalho? Quais as principais diferenças de percepção de professores universitários do Brasil e do Canadá sobre os fatores de QVT? Assim sendo, o objetivo principal deste artigo é avaliar os fatores de qualidade de vida no trabalho para os professores que atuam no Brasil e no Canadá e correlacioná-los com o sentido do trabalho. Como objetivo específico busca-se determinar as principais diferenças em relação aos fatores de QVT para professores universitários nesses dois países.

\section{FUNDAMENTAÇÃO TEÓRICA}

O termo "Qualidade de Vida no Trabalho" foi introduzido pela primeira vez em uma conferência internacional realizada em Arden House em 1972, por Louis Davis. As comunicações que foram apresentadas, em seguida, foram publicadas em dois volumes (Davis \& Cherns, 1975). Esta conferência literalmente lançou todo um campo de pesquisa em desenho do trabalho conhecido como Projeto de Sistemas Sócio Técnico (STSD). QVT é agora um conceito complexo, que combina dois aspectos principais: os fatores - determinantes da QVT e os indicadores - componentes de QVT.

Boisvert (1977) publicou uma análise da qualidade de vida no trabalho com 15 dimensões de QVT: controle ou autonomia no trabalho, capacidade de exercer um juízo, importância das decisões, oportunidades de aprendizagem, uso de habilidades, controle sobre os critérios de desempenho, desafios apresentados no trabalho, variedade de tarefas, interação com os colegas, reconhecimento, orgulho de realização, contribuição do trabalho para os objetivos da organização, percepção de um futuro desejável e participação na tomada de decisões. Esta lista apresenta diferentes dimensões que são ou fatores, como a interação com os colegas, ou indicadores, como 0 orgulho da realização.

Levine (1983) publicou uma medida desenvolvida por meio do método de Delphi em uma amostra representativa de 70 empregados. Foram identificados seis critérios com este método: respeito e confiança dos gerentes com funcionários, variedade de tarefas, desafios no trabalho, promoções justas, equilibrio entre vida profissional e autoestima. Mais uma vez, nesta lista, existem fatores de QVT, como a variedade de tarefas e os indicadores de QVT, como equilíbrio entre vida profissional e autoestima. Mais recentemente, Royuela, LopezTamayo e Surinach (2008) identificaram 10 dimensões que descrevem QVT: valor intrínseco do trabalho, desenvolvimento de competências e habilidades para a carreira, igualdade de gênero, saúde e segurança, inclusão e acesso ao mercado de trabalho, organização do trabalho e equilíbrio trabalho-vida privada, diálogo social e envolvimento dos funcionários, diversidade e não discriminação, e desempenho global. Aqui, também há fatores como o desenvolvimento de competências e habilidades e indicadores como o valor intrínseco do trabalho.

Vale ressaltar que esse artigo trata apenas dos fatores de QVT, pois parte desta pesquisa considerou também os indicadores de QVT, observando inclusive o relacionamento entre o sentido do trabalho e os indicadores de QVT. Os resultados concernentes a esses tópicos podem ser encontrados em Vilas Boas e Morin (2013, 2013a, 2013b, 2013c).

No Brasil, diversos estudos têm sido conduzidos por autores como: Sant'Anna e Kilimnick (2011), Limongi França (2003), De Oliveira e Limongi-França (2005), Constantino (2008), Tolfo e Piccinini (2007) e Sampaio (2012). Entre eles, há exemplos de desenvolvimento e validação de um instrumento genérico de avaliação da Qualidade de Vida, no âmbito dos indicadores biopsicossociais, junto à comunidade da USP. Para este trabalho, Constantino (2008) adaptou um instrumento tendo como base teórica os aspectos biológicos, 
psicológicos e sociais a partir do modelo apresentado por Kertesz e Kerman (1985). Limongi-França (2003) apresenta uma nova modelagem conceitual com base nas interfaces da Gestão da Qualidade de Vida no Trabalho da administração de empresas. Neste trabalho a autora busca oferecer instrumental para subsidiar ações estratégicas, gerenciais e operacionais em nível coletivo e individual nos desafios da busca e reconstrução do bem-estar nas empresas. Tolfo e Piccinini (2007) enfatizam a distinção entre sentido e significado ao trabalho. Para estes autores, o construto sentido do trabalho deve ser estudado em uma perspectiva multidisciplinar, pois se trata de um 'construto psicológico multidimensional e dinâmico'. Adicionalmente, Sampaio (2012: 135) afirma que 'os trabalhos de Estelle Morin e colaboradores são uma nova influência no campo da QVT e trazem aperfeiçoamentos teóricos e técnicos aos modelos clássicos, apesar de sua identificação com os conceitos de bem-estar (principalmente psicológico) e sentidos do trabalho'. Este autor ainda afirma que uma agenda de estudos e pesquisas sobre QVT deve considerar que 'o maior desafio para a QVT é a produção de um conhecimento válido para as novas formas de relações de trabalho e de organização do trabalho'. Porque 'a participação do trabalhador avançou em alguns segmentos, mas permanece tímida nas organizações burocratizadas, rotinizadas e centralizadas, que ainda são numerosas, se considerarmos as organizações de mercado e estado'. Estes e outros estudos mostram que o estudo da QVT ainda carece de muitas pesquisas.

Diante da vasta publicação sobre QVT no Brasil e em outros países, optou-se por dar mais destaque aos estudos internacionais, devido a um trabalho maior que delineou este estudo que utilizou escalas consagradas de temas relacionados que ajudaram a criar um modelo geral de Qualidade de Vida no Trabalho que direcionou a pesquisa comparativa (Morin, 2008). Por conseguinte, muitas das referências internacionais poderiam ser consideradas defasadas, mas diante do modelo geral de QVT estes estudos podem ser considerados relevantes (Vilas Boas \& Morin, 2014b). Além disso, as fontes nacionais são normalmente mais utilizadas pelos pesquisadores brasileiros envolvidos com este tema, e um viés internacional pode trazer contribuições importantes para a gestão de pessoas.

\subsection{Fatores de Qualidade de Vida de Trabalho}

Desde 1993, alguns pesquisadores do CRITEOS-HEC investigam diferentes configurações para determinar as características de um trabalho que tem sentido (Morin, 1997; Morin, 2001; Morin, 2003; Morin \& Cherré, 1999; Morin \& Dassa, 2004). Para descobrir o que dá sentido ao trabalho, setenta e cinco entrevistas semiestruturadas foram realizadas com executivos em cargos de nível médio e superior nas empresas que operam em diversos setores, trinta e seis pessoas na área de Montreal e trinta e nova na região de Paris (Morin, 1997). Durante as entrevistas, os sujeitos tendem a comparar as características do trabalho atual (ou passado) com as características de um trabalho que considero significativo para si. A análise de conteúdo desses setenta e cinco entrevistas identificou catorze características de um trabalho significativo (Morin \& Cherré, 1999). As investigações iniciais identificaram seis componentes principais e as características do trabalho que estariam associados com um trabalho que faz sentido: utilidade social do trabalho, autonomia, oportunidades de aprendizagem, retidão moral, cooperação ou relação com colegas e superiores, e reconhecimento. Esses seis fatores podem ser agrupados como características relacionadas com o trabalho em si ou características das relações de trabalho, descrito a seguir de acordo com Morin e Dassa (2004). Os demais fatores estão relacionados à segurança no trabalho, à carga do trabalho e ao número de horas trabalhadas.

\subsubsection{Características do trabalho}

Segundo Morin and Dassa (2004), as características do trabalho determinam o sentido do trabalho. Para o trabalho ser significativo, é importante fazer algo que seja útil para alguma coisa ou para alguém, ou um trabalho que contribui para os outros ou para a sociedade (Paula et al. 2012. As investigações relacionadas com as diretrizes do trabalho demonstram que as pessoas estão à procura de um trabalho que lhes permita sentir-se necessárias, realizar-se como seres humanos e participar de um trabalho comum (Morin, 2001). Neste contexto, Morin (2008) e Vilas Boas e Morin (2014b) afirmam que certos aspectos do trabalho que dependem da forma de organização do mesmo podem determinar a QVT. Estes aspectos são apresentados em destaque, a fim de dar uma ideia dos mesmos.

Neste contexto, pode-se dizer que a utilidade social do trabalho ou finalidade do trabalho afeta a qualidade de vida no trabalho em diferentes formas e graus. $O$ trabalho deve proporcionar um grau de 
autonomia aos indivíduos, permitindo-lhes exercer as suas competências e julgamentos no desempenho de suas tarefas, criar solução de problemas e ter voz nas decisões que afetam a si mesmos. Autonomia e liberdade levam a um ambiente participativo e positivo, cujas pessoas sentem prazer em trabalhar como uma equipe, mas ao mesmo tempo como um profissional independente. Para o trabalho de ser significativo, ele deve também dar prazer para as pessoas que o executam. Para isso, ele deve coincidir com seus interesses, usar suas habilidades, estimular o desenvolvimento de seu potencial e capacitá-las a alcançar seus objetivos de forma eficaz. Em outras palavras, é preciso oferecer-lhes oportunidades para aprender, crescer e alcançar suas próprias metas e objetivos.

\subsubsection{Características das relações de trabalho}

Para Morin and Dassa (2004), o trabalho tem sentido quando é feito de forma responsável, não só na sua execução, mas também na qualidade dos produtos e das consequências que ele acarreta. Neste contexto, Morin (2008) e Vilas Boas e Morin (2014b) afirmam que o trabalho tem sentido quando ele é realizado em um contexto que respeita os valores do ser humano e em um ambiente que respeita a justiça e a dignidade humana. Retidão moral é uma característica que apareceu em suas investigações como muito importante, mas pouco aparece na literatura sobre a organização do trabalho. É possível que os escândalos em determinado negócio levaram a insights sobre a retidão moral em práticas sociais e organizacionais. Para o trabalho de ser significativo, ele deve ser feito em um ambiente que promova o desenvolvimento de relacionamentos profissionais positivos. Por outro lado, tem que permitir o desenvolvimento de relacionamento com colegas, ajudando uns aos outros quando enfrentam dificuldades. Finalmente, o trabalho é significativo quando se é reconhecido. Reconhecimento e valorização são, de fato, necessários para incentivar o comportamento produtivo e o desenvolvimento da autoestima. Os reforços vêm de muitas formas, como: as palavras de apreço e consideração demonstrada pelos supervisores, 0 apoio que eles dão para que as equipes sejam responsáveis, um tratamento equitativo de salário e benefícios, a disponibilização de um sistema de recompensas eficiente, a influência real das pessoas na tomada de decisões, e autoestima evidenciada pelos colegas de trabalho.

Além destes fatores relacionados às características do trabalho e de relações de trabalho, a sensação de segurança no emprego e a carga de trabalho física, mental e emocional estão relacionadas ao trabalho significativo. Portanto, estes outros fatores devem ser analisados para melhor descrever o papel da qualidade de vida no trabalho no desempenho dos negócios e na satisfação dos funcionários.

\subsubsection{Segurança no trabalho}

O sentimento de segurança no emprego também é importante para descrever a qualidade de vida no trabalho. De acordo com Lori e Barling (2005), o sentimento de segurança no trabalho está associado ao sentimento de estabilidade no trabalho e possibilidade de cumprir com seus compromissos estabelecidos. Por outro lado, a insegurança no trabalho é um conceito que pode ser definido como uma "preocupação com a permanência futura" de uma pessoa em seu trabalho (Van Vuuren \& Klandermans, 1990, p. 133). Assim, a insegurança no trabalho pode ser vista como um estressor com inúmeros resultados negativos (Cheng \& Chan, 2008; Sverke, Hellgren \& Näswall, 2002). Com relação a este foco de insegurança no emprego como um estressor, De Witte (1999) também discute as reações emocionais em relação à futura permanência no emprego. Uma recente meta-análise sobre a insegurança no trabalho realizado por Cheng e Chan (2008) demonstra que a satisfação no trabalho e o comprometimento organizacional são as duas relações mais frequentemente estudadas e as reações mais onipresentes na insegurança no emprego.

A fim de estabelecer a ligação entre insegurança no trabalho e atitudes perante 0 trabalho, Debus, Probst, König e Kleinmann (2012) analisaram uma amostra de 15.200 funcionários de 24 países por meio de uma modelagem multinível. Os autores afirmam que 0 estudo contribui para a literatura sobre a insegurança no emprego, porque as reações a esta questão não são universalmente iguais. Em vez disso, essas reações dependem do contexto cultural e do país em que um profissional está inserido. De Cuyper, Notelaers e De Witte (2009) investigam como a insegurança do emprego e da empregabilidade se relacionam com a satisfação no trabalho e com o comprometimento organizacional afetivo dos trabalhadores permanentes, trabalhadores contratados a termo e trabalhadores temporários. Eles concluíram que as respostas dos trabalhadores temporários em relação à insegurança no emprego foram claramente diferentes das respostas dos trabalhadores contratados a termo. 


\subsubsection{Carga de trabalho}

O estudo da carga de trabalho pode ajudar psicólogos do trabalho e ergonomista a distinguir entre a eficiência dos projetos concorrentes de emprego de sistemas contemporâneos e ajudar os gestores a fornecer um melhor ambiente de trabalho (Gropher \& Donchin, 1986; O'Donnell \& Eggemeier, 1986). Carga de trabalho (workload) também pode ser usada para fornecer insights sobre características específicas de trabalho e das relações de trabalho que levam ao significado do trabalho (Morin, 2008). No final do último milênio, grande parte da literatura sobre a carga de trabalho foi intitulada como o trabalho mental, porém a maioria dos estudos inclui diferentes dimensões da carga de trabalho (Hancock, Rodenberg, Mathews \& Vercruyssen, 1988; Hart \& Staveland, 1988; Kantowitz, 1987; Vidulich \& Tsang, 1986).

Por exemplo, Vidulich e Tsang (1986) utilizam a técnica de avaliação da carga de trabalho, conhecida como NASA-TLX, que avalia a carga de trabalho com 6 dimensões: demanda mental, demanda psíquica, demandas temporais, esforço, desempenho e frustração. Os pesos de cada componente variam entre zero e cinco. O Índice de Carga de Tarefas (NASA TLX) é também descrito em detalhe por Hart e Staveland (1988).

Percepções subjetivas de carga de trabalho refletem uma avaliação da capacidade do indivíduo para atender às demandas da tarefa. Altos níveis de carga de trabalho percebida ocorrem quando as demandas de tarefas excedem a capacidade do indivíduo para atender a essas demandas. Neste contexto, alguns estudos demonstraram que os períodos de baixa carga de trabalho podem causar fadiga, se 0 indivíduo necessita manter a atenção sobre a tarefa por um período de tempo prolongado (Matthews et al., 2002). Outros estudos demonstraram que os períodos de elevada carga de trabalho podem causar fadiga (Hancock \& Verwey, 1997, Matthews \& Desmond, 2002). Como consequência, esse estado de fadiga causa deficiências na motivação e no desempenho, e problemas de saúde, bem-estar e segurança (Grech, Neal, Yeo, Humphreys \& Smith, 2009; Zohar, Tzischinski, \& Epstein, 2003).

\subsubsection{Horas trabalhadas}

Na pesquisa nacional realizada com acadêmicos no Reino Unido, Kinman e Jones (2008) observaram que muitos professores e pesquisadores no Reino Unido estão trabalhando em excesso, ultrapassando o limite de 48 horas semanais estabelecido pela diretiva relativa ao tempo de trabalho na União Europeia. Essas "descobertas sugerem que os acadêmicos estão frequentemente trabalhando durante a noite e fins de semana, a fim de lidar com as demandas de seu trabalho. 0 potencial de impacto dessa prática sobre a saúde do empregado e a sua vida familiar foi destacado aqui." (Kinman \& Jones, 2008, p. 54). Estes autores observaram, também, que as horas de trabalho acadêmicos durante as noites e fins de semana podem levar a problemas físicos e psicológicos, menos distinção entre as fronteiras do trabalho e dos domínios de casa, e mais conflito vida-trabalho (Kinman \& Jones, 2008, pp. 54-55).

Virtanen, Vahtera, Nakari, Pentii e Kivimaäki (2009) observaram que trabalhar mais de 55 horas por semana gera distúrbios do sono em funcionários que antes eram livres de tais distúrbios no início do referido período de trabalho. Estes autores concluíram que "um ajuste nas demandas de trabalho pode levar a mais controle, porque altas demandas e longas horas de trabalho podem representar 2 indicadores do mesmo ambiente de trabalho estressante, em vez de dois fatores de risco distintos" (Virtanen et al., 2009, p. 742). Estes resultados são relevantes porque os distúrbios do sono podem ter um efeito negativo significativo sobre a qualidade de vida de um indivíduo, e as consequências associadas aos distúrbios do sono são graves, incluindo, por exemplo, um maior risco de acidentes devido ao cansaço e ao estresse.

No ambiente acadêmico, professores e pesquisadores estão trabalhando longas horas, a fim de atender aos requisitos de ensino e publicação. Essa situação tem aumentado o risco de perda do equilíbrio entre a vida profissional e a vida privada, devido ao estresse causado pelas longas horas de trabalho e as cobranças constantes de produtividade (Winefield et al., 2003; Gillespie et al., 2001). Principalmente, porque hoje em dia os professores são vistos mais como pesquisadores do que como professores propriamente dito (Vannini, 2006). Portanto, a sua saúde mental pode estar em risco, também, por causa do estresse e da fadiga que experimentam no seu trabalho e da falta de equilíbrio vida-trabalho. 


\subsubsection{O sentido do trabalho}

O sentido de trabalho está relacionado com a forma como as pessoas compreendem a sua experiência nas organizações. De acordo com Wrzesniewski, Dutton e Debebe (2003, p. 99), o sentido do trabalho pode ser definido "como o entendimento dos empregados daquilo que eles fazem no trabalho assim como a importância do que eles realmente fazem". Ambos os aspectos do sentido do trabalho estão relacionados às crenças de uma pessoa sobre a função que o trabalho desempenha na sua vida, que é afetada pelo contexto social.

Pratt e Ashforth (2003, p. 104) propõem um "modelo de distinção entre sentido do trabalho e sentido no trabalho". Neste modelo, o primeiro está relacionado com as características do trabalho e o segundo com as relações estabelecidas no trabalho. $O$ que permite que ao indivíduo responder às seguintes perguntas: $O$ que eu faço? Quem sou eu? e Por que estou aqui? Pratt e Ashforth (2003) apresentam a hipótese de que o sentido que o indivíduo dá ao seu trabalho e seu ambiente de trabalho está relacionada com a sua própria identidade. Vale a pena dizer que Wrzesniewski et al. (2003, p. 99) também afirmam que "os funcionários são motivados a obter um sentido para seus esforços".

Outros estudos similares buscaram analisar a relação entre o significado do trabalho e os indicadores de QVT. Nestes estudos, observou-se que existe uma relação significativa positiva entre o sentido do trabalho e o sentido no trabalho de um lado e o bem-estar psicológico, o comprometimento afetivo, o comprometimento com o trabalho e o equilibrio trabalho-vida privada de outro lado. Observou-se também que existe uma relação negativa significativa entre o sentido do trabalho e o sentido no trabalho de um lado e o sofrimento psicológico, presenteísmo, estresse relacionado ao trabalho e comprometimento de continuidade do outro (Vilas Boas \& Morin, 2013, 2013a, 2013b, 2013c).

\section{METODOLOGIA}

Os questionários foram enviados através Survey Monkey no primeiro semestre de 2013. O questionário foi enviado para: 625 professores da Universidade Federal de A (UFA); 378 professores da Universidade Federal de B (UFB); 995 professores da Universidade Federal de C (UFC); 1.058 professores da Universidade du Quebec à A (UQA); 414 professores da Universidade du Quebec à B (UQB), e 207 professores da Universidade du Quebec à $C$ (UQC). Ao todo, 526 professores responderam o questionário, 106 UFA (taxa de resposta de 20,2\%), 63 UFB (taxa de resposta de 12,0\%), 105 UFC (taxa de resposta de 20,0\%), 156 de UQA (taxa de resposta de 29,7\%), 59 UQB (taxa de resposta 11,2\%) e 37 UQC (taxa de resposta de 7,0\%). As taxas de retorno foram baixas em cada universidade, por isso, é difícil realizar uma análise separada por universidade. Mas, em relação ao total de questionários em cada país, há dados suficientes para fazer as análises comparativas.

Entre os respondentes, 248 eram mulheres e 278 eram homens. Há uma diferença significativa entre as distribuições de gênero no Brasil em comparação com o Canadá. No Brasil, havia 106 mulheres e 178 homens, enquanto no Canadá, havia 142 mulheres e 110 homens. Assim, a amostra no Brasil tem um viés de gênero em favor dos homens.

Os professores que se voluntariaram para responder a pesquisa tinham em média 45,07 anos de idade (DP 10,481). Há uma diferença significativa na idade dos respondentes entre brasileiros e canadenses $(t=-$ $6,512, \mathrm{df}=669, p<.000)$. Na verdade, entre os brasileiros $(\mathrm{N}=274)$ a idade média é de 42,63 anos (DP 9,967) e entre os canadenses $(N=252)$ a idade média é de 47,72 anos (DP 10,286). Em outras palavras, os professores brasileiros que responderam à pesquisa eram mais jovens do que os canadenses. Isso não significa, necessariamente, que os professores brasileiros são, em geral, mais jovens que os canadenses, já que não há dados demográficos para toda a população de professores nos dois países.

Nesta amostra, 17,9\% dos professores têm mestrado, 71,9\% têm doutorado e 10,3\% possuem pósdoutorado. Quanto ao estado civil, $15,6 \%$ eram solteiros, $78,4 \%$ eram casados ou viviam com um parceiro, $5,3 \%$ eram separados ou divorciados e $0,4 \%$ eram viúvos. Entre os entrevistados de ambos os países, $64,1 \%$ têm filhos e a maioria deles têm duas crianças $(30,2 \%)$, em seguida uma criança $(18,8 \%)$ e 3 crianças $(12,0 \%)$. A maioria dos participantes $(99,4 \%)$ são professores de tempo integral e apenas 10,3\% não possuem título de doutorado ou de $\mathrm{PhD}$. No entanto, $37,1 \%$ dos professores que participaram desta pesquisa são professores adjuntos, $26,6 \%$ são professores associados e $19,6 \%$ são professores titulares. Os demais respondentes $(5,9 \%)$ não informaram o seu status ou posição na instituição. 
O questionário foi concebido para avaliar a qualidade de vida no trabalho para os professores universitários. Mais especificamente, ele inclui escalas que medem os seguintes fatores: o próprio trabalho com foco em características de trabalho (11 afirmativas) e características das relações de trabalho ( 15 afirmativas) de acordo com a escala elaborada por Morin e Dassa (2004). Os entrevistados foram solicitados a informar em que grau eles concordaram com as demonstrações, usando um formulário de 5 opções variando na escala "Concordo totalmente" a "Discordo totalmente". A sensação de segurança no trabalho foi medida pela escala de Lori e Barling (2005), que contém 4 afirmativas. A carga de trabalho teve como objetivo medir a carga de trabalho físico (tempo para executar suas tarefas), carga mental (tarefas complexas) e carga emocional (trabalho emocional relacionado ao relacionamento humano) com base nos estudos de Vidulich e Tsang (1986) e Morin (2008). A escala de carga de trabalho era composta de 15 afirmativas com 6 opções de resposta, podendo variar de "Jamais - Nenhuma vez" até "O tempo todo - Todo dia". Além disso, os professores foram solicitados a informar o número de horas trabalhadas por dia e por semana e responder outras questões relacionadas com a sua atividade profissional.

Devido à complexidade dos estudos sobre QVT, sugere-se que em pesquisas futuras seja observado também o grau de satisfação, grau de esforço, horas de descanso e vocação para a atividade, combinadas com indicadores de capacidade para o trabalho, conforme destaca Lennart Levi e outros estudiosos da Psicologia do Trabalho que focam a saúde e o stress no trabalho, como postulam Rosch (2012), Ilmarinen, Tuomi e Seitsamo (2005) e Martinez, Latorre e Fischer (2010). Adicionalmente, vale lembrar que este estudo faz parte de um estudo mais amplo que também aborda alguns destes aspectos.

Para cada escala do questionário, a análise de componente principal, com rotação ortogonal de fatores, foi realizada a fim de reduzir as variáveis observadas para um número mínimo de dimensões (ou componentes) que descrevem a proporção máxima de variação para cada uma das variáveis. A estrutura fatorial das escalas foi então testada com uma análise dos eixos principais com rotação ortogonal. Foi analisada a consistência interna de cada fator, a fim de avaliar a sua confiabilidade, utilizando o alfa de Cronbach. Antes de testar as diferenças entre os dois grupos de professores, foi examinada consistência dos fatores, a fim de validar 0 modelo de QVT que se pretendia usar utilizando o coeficiente de Pearson. A parte dessas análises, foi possível discutir a relação entre fatores de QVT nas universidades de Minas Gerais e do Quebec. A diferença de médias entre os dois grupos foi finalmente examinada usando o procedimento de teste $T$ e os efeitos de tamanho dessas diferenças foram calculados quando foram identificadas diferenças significativas de médias.

\section{RESULTADOS E DISCUSSÃO}

\subsection{A relação entre os fatores de QVT}

Como foi previamente definido, QVT é um estado geral de bem-estar no local de trabalho. Portanto, a QVT pode ser medida por indicadores e fatores de qualidade. Se os fatores são consistentes, os índices de consistência serão fortemente correlacionados e em uma direção consistente da QVT. Os professores que perceberam uma alta qualidade de vida no trabalho na sua universidade devem obter escores elevados para a finalidade do trabalho, autonomia e desenvolvimento profissional e altos escores para as relações com colegas, retidão moral e reconhecimento. Eles devem obter pontuação positiva para a segurança no emprego. Eles também devem obter baixas contagens para cargas de trabalho. Além disso, as inter-correlações entre estes fatores devem ser significativas e em uma direção consistente, por exemplo, as oportunidades de desenvolvimento profissional e reconhecimento devem ser positivamente correlacionadas e 0 coeficiente de Pearson deve ser significativo.

A Tabela 1 apresenta as médias, os desvios padrão, os coeficientes de correlação de Pearson, 0 número de itens para cada indicador e o índice de consistência interna determinada pelo alfa de Cronbach. Como demonstram os resultados apresentados nesta tabela, os coeficientes de correlação são significativos e na direção esperada, mostrando a consistência das informações que essas medidas apresentam. Os fatores de QVT escolhidos oferecem informações confiáveis (porque os índices de consistência interna são maiores do que 0,70 , exceto para segurança de trabalho, que é 0,655 ) e informações consistentes (porque os coeficientes de Pearson são significativos e na direção esperada).

\subsubsection{Os construtos principais}


Existe uma correlação moderada - positiva - entre a autonomia no trabalho e a finalidade do trabalho $(0,322, p<0,000)$. 0 tamanho do coeficiente de correlação de Pearson significa que os dois indicadores avaliam aspectos diferentes da QVT e dão informação consistente ou coerente sobre a variável latente que é suposto representar, isto é, a QVT (Tabela 1). Da mesma forma, existe uma forte correlação - positiva - entre as oportunidades de desenvolvimento profissional e a finalidade ou propósito do trabalho $(0,536, p<0,000)$, mas 0 tamanho do coeficiente de Pearson não é suficientemente elevado para identificar um com o outro fator. Da mesma forma, há uma correlação forte - positiva - entre o desenvolvimento profissional e a autonomia $(0,563, p$ $<0,000)$. Essas relações indicam claramente que eles são diferentes fatores que podem determinar as relações entre as características do trabalho.

Há uma forte correlação - positiva - entre retidão moral e relações com os colegas $(0,716, p<0,000)$, mas não alto o suficiente para confundir os dois fatores. Além disso, há uma forte correlação - positiva - entre Reconhecimento e Relações com os colegas $(0,664, p<0,000)$ e Retidão moral $(0,666, p<0,000)$, indicando claramente que eles são diferentes fatores que podem determinar as relações entre as próprias relações de trabalho. Existem ainda correlações fracas - positivas - entre Segurança no trabalho, Propósito, Autonomia, Desenvolvimento profissional, Retidão moral e Reconhecimento (respectivamente 0,$178 ; 0,269 ; 0,174 ; 0,150$ e $0,194, p<0,000)$. No entanto, não há correlação significativa entre 0 sentimento de segurança de trabalho e as cargas de trabalho dando informações consistentes sobre a percepção dos professores sobre a QVT. Essa constatação se deve ao fato que os professores já percebem um forte sentimento de segurança, porque 0 trabalho neste tipo de organização é muito seguro devido à estabilidade no setor público.

Pode-se observar também correlações fracas - negativas - entre carga física e todas as características de trabalho $(-0,130 ;-0,224 ;-0,168 ;-0,192 ;-0,200$ e $-0,226, p<0,000)$, indicando claramente que eles são fatores consistentes de determinação da QVT. Por outro lado, há uma fraca correlação - positiva - entre Carga Mental e Propósito $(0,172, p<0,000)$, o que indica claramente que há duas maneiras possíveis para entender a relação entre esses fatores de QVT. No entanto, há uma correlação - negativa - um pouco fraca, mas significativa, entre Carga Mental e Desenvolvimento Profissional $(-0,124, p<0,000)$.

Há ainda correlações fracas - negativas - entre carga emocional e todas as características de trabalho (0,$095 ;-0,300 ;-0,204 ;-0,300 ;-0,353$ e $-0,305, p<0,000$ ), indicando claramente que eles são fatores consistentes na determinação da QVT. Além disso, existem correlações fracas - negativas - entre horas trabalhadas por dia e por semana, e os fatores de características do trabalho e das relações, tais como autonomia, retidão moral e reconhecimento. No entanto, existem correlações fracas - positivas - entre as horas trabalhadas e as cargas de trabalho, indicando claramente que quando as horas de trabalho diminuem, as cargas de trabalho diminuem; e quando as horas de trabalho aumentam, as cargas de trabalho também aumentam, como preconizado no modelo em estudo. 
Tabela 1: Médias, desvio padrão, correlação de Pearson entre os fatores de QVT, índices de consistência interna e número de itens ( $\mathrm{N}=526)$

\begin{tabular}{|c|c|c|c|c|c|c|c|c|c|c|c|c|c|c|c|}
\hline FATORES & $\begin{array}{l}\text { Mé- } \\
\text { dias }\end{array}$ & SD & & $\begin{array}{l}\text { Pur } \\
\text { pose }\end{array}$ & $\begin{array}{l}\text { Auto } \\
\text { nomy }\end{array}$ & $\begin{array}{l}\text { Sef } \\
\text { Dev }\end{array}$ & $\begin{array}{l}\text { Rela } \\
\text { tions }\end{array}$ & $\begin{array}{c}\text { Rec } \\
\text { Moral }\end{array}$ & $\begin{array}{l}\text { Recog } \\
\text { nition }\end{array}$ & $\begin{array}{l}\text { JobSe } \\
\text { curity }\end{array}$ & $\begin{array}{l}\text { Char } \\
\text { Phys }\end{array}$ & $\begin{array}{l}\text { Char } \\
\text { Ment }\end{array}$ & $\begin{array}{l}\text { Char } \\
\text { Emot }\end{array}$ & $\begin{array}{c}\text { Hours } \\
\text { Day }\end{array}$ & $\begin{array}{l}\text { Hours } \\
\text { Week }\end{array}$ \\
\hline \multirow[t]{2}{*}{ PURPOSE } & 55.32 & 5.22 & (Alpha) & $(, 705)$ & & & & & & & & & & & \\
\hline & & & ( $\mathrm{N}^{\circ}$ itens) & (3) & & & & & & & & & & & \\
\hline \multirow[t]{2}{*}{ AUTONOMY } & 51.46 & 7.47 & r & ,322 & $(.825)$ & & & & & & & & & & \\
\hline & & & Sig. (bil) & ,000 & (3) & & & & & & & & & & \\
\hline \multirow[t]{2}{*}{ SELFDEV } & 53.14 & 7.24 & r & ,536 & ,563 & $(.858)$ & & & & & & & & & \\
\hline & & & Sig. (bil) &, 000 &, 000 & (3) & & & & & & & & & \\
\hline \multirow[t]{2}{*}{ RELATIONS } & 46.49 & 8.67 & r & 431 & ,404 & ,483 & $(.892)$ & & & & & & & & \\
\hline & & & Sig. (bil) &, 000 &, 000 &, 000 & (6) & & & & & & & & \\
\hline \multirow[t]{2}{*}{ RECMORAL } & 46.62 & 10.07 & r & ,312 & ,457 & 469 & ,716 & $(.914)$ & & & & & & & \\
\hline & & & Sig. (bil) &, 000 &, 000 &, 000 & ,000 & (4) & & & & & & & \\
\hline \multirow[t]{2}{*}{ RECOGNITION } & 43.61 & 9.69 & r & 340 & ,537 & ,544 & 664 & ,666 & $(.756)$ & & & & & & \\
\hline & & & Sig. (bil) &, 000 &, 000 &, 000 & ,000 &, 000 & (4) & & & & & & \\
\hline \multirow[t]{2}{*}{ JOBSECURITY } & 50.56 & 7.62 & r & 178 & ,269 & ,174 & 166 & , 150 & ,194 & $(.655)$ & & & & & \\
\hline & & & Sig. (bil) &, 000 &, 000 & ,000 & ,000 &, 001 &, 000 & (4) & & & & & \\
\hline \multirow[t]{2}{*}{ CHARPHYS } & 35.45 & 9.44 & r &,- 130 &,- 224 &,- 168 &,- 192 &,- 200 &,- 226 &,- 071 & $(.876)$ & & & & \\
\hline & & & Sig. (bil) & ,003 &, 000 &, 000 & ,000 &, 000 &, 000 & , 108 & (5) & & & & \\
\hline \multirow[t]{2}{*}{ CHARMENT } & 50,00 & 8,14 & r & 172 &,- 045 &,- 124 & 073 &,- 001 &,- 018 &,- 012 & ,136 & $(.809)$ & & & \\
\hline & & & Sig. (bil) &, 000 & ,311 &, 005 & ,096 &, 974 & ,685 & ,780 & ,002 & (4) & & & \\
\hline \multirow[t]{2}{*}{ CHAREMOT } & 32.05 & 8.28 & $r$ &,- 095 &,- 300 &,- 204 &,- 300 &,- 353 &,- 305 &,- 056 & ,389 & ,241 & (.774) & & \\
\hline & & & Sig. (bil) & ,031 &, 000 &, 000 & ,000 &, 000 &, 000 & 199 &, 000 & ,000 & (5) & & \\
\hline
\end{tabular}




\begin{tabular}{|c|c|c|c|c|c|c|c|c|c|c|c|c|c|c|c|}
\hline FATORES & $\begin{array}{l}\text { Mé- } \\
\text { dias }\end{array}$ & SD & & $\begin{array}{l}\text { Pur } \\
\text { pose }\end{array}$ & $\begin{array}{l}\text { Auto } \\
\text { nomy }\end{array}$ & $\begin{array}{l}\text { Sef } \\
\text { Dev }\end{array}$ & $\begin{array}{l}\text { Rela } \\
\text { tions }\end{array}$ & $\begin{array}{c}\text { Rec } \\
\text { Moral }\end{array}$ & $\begin{array}{l}\text { Recog } \\
\text { nition }\end{array}$ & $\begin{array}{l}\text { JobSe } \\
\text { curity }\end{array}$ & $\begin{array}{l}\text { Char } \\
\text { Phys }\end{array}$ & $\begin{array}{l}\text { Char } \\
\text { Ment }\end{array}$ & $\begin{array}{l}\text { Char } \\
\text { Emot }\end{array}$ & $\begin{array}{c}\text { Hours } \\
\text { Day }\end{array}$ & $\begin{array}{l}\text { Hours } \\
\text { Week }\end{array}$ \\
\hline HOURS/DAY & 9,13 & 1,581 & $\mathrm{R}$ & ,052 & -,208 &,- 097 & .015 & -.112 & -.116 &,- 077 & ,221 & ,102 & ,123 & (.) & \\
\hline$(\mathrm{N}=495)$ & & & Sig. (bil) &, 250 &, 000 & ,031 & ,741 &, 012 & ,010 & 087 &, 000 & ,023 &, 006 & (1) & \\
\hline HOURS/WEEK & 49,34 & 11,571 & $\mathrm{R}$ & ,029 &,- 140 &,- 043 & ,005 &,- 110 &,- 094 &,- 065 &, 268 &, 064 & ,107 &, 764 & (.) \\
\hline$(\mathrm{N}=495)$ & & & Sig. (bil) &, 519 & ,002 & ,345 & ,904 & 014 & ,037 & ,148 &, 000 & ,156 &, 017 &, 000 & (1) \\
\hline
\end{tabular}

Fonte: Dados da pesquisa

Nota. Finalidade do trabalho (PURPOSE), Autonomia (AUTONOMY), Desenvolvimento profissional (SELFDEV), Relações com os colegas (RELATIONS), Retidão moral (RECMORAL), Reconhecimento (RECOGNITION), Segurança no trabalho (JOBSECURITY), Carga física (CHARPHYS), Carga mental (CHARMENT), Carga emocional (CHAREMOT), Número de horas trabalhadas por dia (HOURS/DAY), e Número de horas trabalhadas por semana (HOURS/WEEK). 


\subsubsection{Os construtos aparentes}

A fim de entender melhor a relação entre as características do trabalho, as características das relações de trabalho, a sensação de segurança no emprego e os diferentes tipos de carga de trabalho que estariam associados a um trabalho que tem sentido, calcularam-se as correlações entre estas variáveis. Em geral, a Tabela 2 mostra que quase todos esses fatores estão significativamente correlacionados com indicadores de sentido do trabalho como preconizado pelo modelo de pesquisa adotado (Morin, 2008).

Em síntese, esperava-se uma relação significativa positiva entre o sentido do trabalho e o sentido no trabalho de um lado, e o propósito do trabalho, autonomia, desenvolvimento profissional, retidão moral, relações com os colegas, reconhecimento e segurança no trabalho por outro lado. Estes são os resultados que foram obtidos nesta amostra de professores universitários, como pode ser observado na Tabela 2. Esperava-se também uma relação negativa significativa entre o sentido do trabalho e o sentido no trabalho de um lado, e a carga física, carga mental e carga emocional por outro lado. Estes são também os resultados que foram obtidos, exceto para a carga mental, que apresentou correlação positiva provavelmente devido à natureza do trabalho acadêmico (Tabela 2). Além disso, a carga física não apresentou correlação significativa com o sentido no trabalho. As correlações mais elevadas ficaram para relações com os colegas $(, 563)$ e para finalidade do trabalho $(, 496)$.

Tabela 2: Coeficientes de correlação de Pearson entre o sentido do trabalho e os fatores de QVT

\begin{tabular}{|c|c|c|c|c|c|c|c|c|c|c|c|}
\hline & & 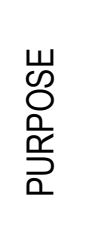 & 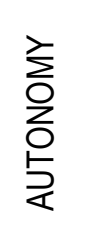 & $\begin{array}{l}\vec{u} \\
\text { 崖 } \\
\text { 㟧 }\end{array}$ & 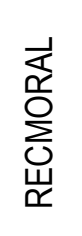 & 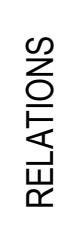 & 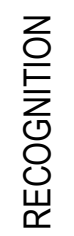 & 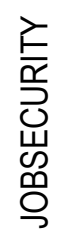 & 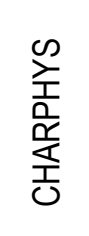 & 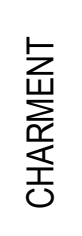 & 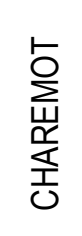 \\
\hline \multirow{3}{*}{$\begin{array}{l}\text { Sentido do } \\
\text { trabalho }\end{array}$} & $r$ & ,496 & ,251 & ,453 & 310 & 339 & 360 & 107 &,- 163 & ,093 & $-1,128$ \\
\hline & Sig & ,000 & ,000 & ,000 & ,000 & ,000 & ,000 & ,014 & 000 & ,034 & ,003 \\
\hline & $\mathrm{N}$ & 525 & 525 & 525 & 525 & 525 & 525 & 519 & 520 & 520 & 520 \\
\hline \multirow{3}{*}{$\begin{array}{l}\text { Sentido no } \\
\text { trabalho }\end{array}$} & $r$ & ,332 & 157 & ,315 & 464 & ,563 & 424 & ,012 &,- 081 & 113 &,- 170 \\
\hline & Sig & ,000 & ,000 & ,000 & ,000 & ,000 & ,000 & ,779 & ,066 & ,010 & ,000 \\
\hline & $\mathrm{N}$ & 525 & 525 & 525 & 525 & 525 & 525 & 519 & 520 & 520 & 520 \\
\hline
\end{tabular}

Fonte: Dados da pesquisa

Nota. Finalidade do trabalho (PURPOSE), Autonomia (AUTONOMY), Desenvolvimento profissional (SELFDEV), Relações com os colegas (RELATIONS), Retidão moral (RECMORAL), Reconhecimento (RECOGNITION), Segurança no trabalho (JOBSECURITY), Carga física (CHARPHYS), Carga mental (CHARMENT) e Carga emocional (CHAREMOT).

\subsection{Fatores de QVT avaliados pelos professores universitários}

Em geral, os professores brasileiros e canadenses sentem que têm uma boa qualidade de vida no trabalho frente aos fatores de QVT. O trabalho em si fornece as oportunidades de desenvolvimento profissional, reconhecimento e desenvolvimento de boas relações com os colegas. Eles podem ver a utilidade social do seu trabalho (propósito de trabalho) e percebem altos escores de autonomia. Além disso, a retidão moral é bem avaliada pelos professores no Brasil, bem como no Canadá. À primeira vista, parece que este é um ambiente de trabalho de 
alta qualidade. Mas tendo observado isso, será que existem diferenças significativas entre os professores brasileiros e canadenses?

\subsubsection{Comparação de percepção entre professores brasileiros e canadenses}

Para saber se os professores brasileiros avaliam os fatores de QVT diferentemente dos professores canadenses, calculou-se a diferença de médias dos fatores utilizando o teste t para amostras independentes. A Tabela 3 apresenta as estatísticas descritivas para os dois grupos e 0 teste t para cada fator. Quando 0 índice de significação bilateral ou p foi menor do que $5 \%$ para todos os fatores, rejeitou-se a hipótese nula $(\mathrm{Ho})$ de que as duas amostras são iguais, e aceitou-se a hipótese alternativa $(\mathrm{Ha})$ de que as amostras de professores brasileiros e canadenses são diferentes para sete fatores de QVT.

Neste estudo sobre os fatores de QVT e o sentido do trabalho, o teste t permitiu encontrar diferenças significativas em sete fatores: autonomia, desenvolvimento profissional, retidão moral, reconhecimento, carga física, carga mental e número de horas trabalhadas por dia (Tabela 3). Em estudos semelhantes sobre QVT, o teste $\mathrm{t}$ permitiu encontrar diferenças significativas de médias em cinco indicadores: significado no trabalho, estresse relacionado ao trabalho, comprometimento afetivo, comprometimento instrumental e equilíbrio trabalho-vida (Vilas Boas \& Morin, 2013, 2013c). Estes estudos mostraram que os professores brasileiros percebem mais QVT em sua universidade do que os professores canadenses, considerando os indicadores de QVT.

0 tamanho do efeito é utilizado para determinar o valor da média das diferenças entre os dois grupos. Ele é determinado com o cálculo de eta quadrado ( $\eta 2$ ). 0 tamanho do efeito para a autonomia é de 0,14 (médio), para 0 desenvolvimento profissional é de 0,05 (pequeno), para retidão moral é de 0,02 (pequeno), para o reconhecimento é de 0,03 (pequeno), para a carga física é de 0,03 (pequeno), para a carga mental é 0,02 (pequeno) e para o número de horas trabalhadas por dia é de 0,03 (pequeno).

Considerando-se os resultados obtidos para esses dois grupos, pode-se dizer que os canadenses têm uma melhor avaliação dos fatores de QVT que a avaliação feita pelos professores brasileiros. Os professores canadenses têm mais autonomia no trabalho e oportunidades para o desenvolvimento profissional do que os professores brasileiros. Os canadenses tendem a encontrar mais retidão moral e reconhecimento do que os brasileiros. Eles também são capazes de controlar melhor suas relações emocionais no local de trabalho do que os seus colegas brasileiros, mas a sua carga física é maior. No entanto, os professores brasileiros tendem a sentir mais carga mental e trabalham mais horas por dia do que os canadenses.

Revista Alcance - Eletrônica - vol. 23 - n. 3 - jul./set. 2016 
Tabela 3: Diferenças de médias de percepção entre 274 professores brasileiros e 252 professores canadenses

\begin{tabular}{|c|c|c|c|c|c|c|}
\hline \multirow[b]{2}{*}{ FATORES } & \multirow[b]{2}{*}{ Nacionalidade } & \multirow{2}{*}{$\begin{array}{l}X \\
\text { Média }\end{array}$} & \multicolumn{2}{|l|}{ S } & \multicolumn{2}{|l|}{ DII } \\
\hline & & & $\begin{array}{l}\text { Desvio } \\
\text { Padrão }\end{array}$ & $\mathbf{t}$ & $\begin{array}{l}\text { Graus de } \\
\text { liberdade }\end{array}$ & Sig (bi) \\
\hline \multirow[t]{2}{*}{ Finalidade } & Brasileiros & 55,5433 & ,45623 & 1,017 & 523 &, 310 \\
\hline & Canadenses & 55,0794 & ,45892 & & & \\
\hline \multirow[t]{2}{*}{ Autonomia } & Brasileiros & 48,7790 & ,60548 & $-9,309$ & 512,036 & ,000 \\
\hline & Canadenses & 54,3651 &, 60005 & & & \\
\hline \multirow[t]{2}{*}{ Desenvolvimento professional } & Brasileiros & 51,5751 & 61703 & $-5,300$ & 521,626 & ,000 \\
\hline & Canadenses & 54,8280 & ,61380 & & & \\
\hline \multirow[t]{2}{*}{ Relações com os colegas } & Brasileiros & 46,8559 & 75747 & 1,001 & 523 & ,317 \\
\hline & Canadenses & 46,0979 &, 76464 & & & \\
\hline \multirow[t]{2}{*}{ Retidão moral } & Brasileiros & 45,7326 & 8,87671 & $-2,102$ & 513,410 & ,036 \\
\hline & Canadenses & 47,5794 & ,87870 & & & \\
\hline \multirow[t]{2}{*}{ Reconhecimento } & Brasileiros & 41,9048 & ,83294 & $-4,260$ & 508,162 &, 000 \\
\hline & Canadenses & 45,4663 & ,83599 & & & \\
\hline \multirow[t]{2}{*}{ Segurança no trabalho } & Brasileiros & 50,4011 & ,66968 &,- 502 & 517 & 616 \\
\hline & Canadenses & 50,7371 & ,67282 & & & \\
\hline \multirow[t]{2}{*}{ Carga física } & Brasileiros & 33,8731 & ,81676 & $-3,969$ & 512,578 & ,000 \\
\hline & Canadenses & 37,1190 & ,81780 & & & \\
\hline \multirow[t]{2}{*}{ Carga mental } & Brasileiros & 51,2127 & 70631 & 3,517 & 503,062 & ,000 \\
\hline & Canadenses & 48,7202 &, 70873 & & & \\
\hline \multirow[t]{2}{*}{ Carga emocional } & Brasileiros & 32,5373 & 72598 & 1,396 & 518 & ,163 \\
\hline & Canadenses & 31,5238 &, 72560 & & & \\
\hline \multirow[t]{2}{*}{$\mathbf{N}^{\circ}$. de horas de trab. por dia } & Brasileiros & 9,39 & 140 & 3,902 & 491,421 & ,000 \\
\hline & Canadenses & 8,85 & 140 & & & \\
\hline \multirow[t]{2}{*}{$\mathrm{N}^{\circ}$. de horas de trab. por semana } & Brasileiros & 49,83 & 1,040 & 966 & 493 & ,335 \\
\hline & Canadenses & 48,83 & 1,040 & & & \\
\hline
\end{tabular}

Fonte: Dados da pesquisa

\subsubsection{Autonomia e fatores de QVT}

Uma análise de regressão linear foi realizada, controlada pela tendência desejabilidade social. As variáveis que foram escolhidas para a análise foram as seguintes: sexo, idade, finalidade do trabalho, desenvolvimento profissional, retidão moral, reconhecimento e relações com os colegas. A análise de regressão linear, passo a passo, revela que as variáveis que melhor explicam os índices de autonomia são: oportunidades de desenvolvimento profissional, reconhecimento, idade e retidão moral. 0 modelo de regressão obtido está apresentado na Tabela 4. 
Este modelo explica $41,1 \%$ da variância na pontuação de Autonomia. Vale a pena observar que todos os fatores da organização do trabalho retidos nessa regressão estão positivamente relacionados aos escores de autonomia, como esperado do modelo de QVT. As outras variáveis não foram retiradas a partir da equação de regressão.

Estes resultados significam que, depois de controlar o viés de conformidade, a pontuação para autonomia é melhor prevista pelo desenvolvimento profissional (positivo, que é mais autonomia, mais desenvolvimento profissional; esta variável é o mais forte preditor de todos aqueles que foram testados nesta regressão e nas demais regressões que foram feitas, mas não foram incluídas neste artigo), reconhecimento (muito positivo) e idade (o que significa que, com o passar do tempo, os professores desenvolvem mais autonomia em seu trabalho).

É de notar que o gênero não foi retido na equação, sugerindo que os homens e as mulheres têm mais ou menos a mesma percepção de autonomia no ambiente de trabalho, mas esta variável ajuda a explicar as diferenças individuais e as atitudes em relação ao trabalho.

Tabela 4: Análise de regressão linear, passo a passo, para prever a pontuação de Autonomia com as variáveis sexo, idade, finalidade do trabalho, desenvolvimento profissional, retidão moral, reconhecimento e relação com os colegas, controlada para Viés de Conformidade $(n=526)$

\begin{tabular}{llllll}
\hline $\begin{array}{l}\text { Modelo com os } \\
\text { fatores retidos }\end{array}$ & $\begin{array}{l}\text { B } \\
\text { Coeficientes não- } \\
\text { estandardizados }\end{array}$ & $\begin{array}{l}\text { SEB } \\
\text { Erro padrão }\end{array}$ & $\begin{array}{l}\mathbf{B} \\
\text { Bêta }\end{array}$ & $\mathbf{R}^{2}$ & $\begin{array}{l}\mathbf{s r}^{2} \\
\text { Erro padrão da } \\
\text { estimativa }\end{array}$ \\
\hline (Constante) & 15,814 & 3,049 &, 411 & 5,73256 \\
Viés de conformidade &,- 054 &, 132 &,- 014 & & \\
$\begin{array}{l}\text { Desenvolvimento } \\
\text { profissional }\end{array}$ &, 371 &, 042 &, 360 & \\
Reconhecimento &, 198 &, 037 &, 257 & \\
Idade &, 093 &, 024 &, 130 & \\
Retidão moral &, 082 &, 034 &, 111 & & \\
\hline
\end{tabular}

Fonte: Dados da pesquisa

Nota. $p<.05$

\subsection{Discussão}

A pesquisa demandou que professores brasileiros e canadenses avaliassem a sua QVT, para posteriormente comparar as percepções destes profissionais sobre o assunto em questão. Em geral, os dois grupos parecem apreciar a qualidade de vida no trabalho nas suas respectivas universidades. No entanto, há uma pequena diferença entre a avaliação que foi feita por brasileiros e canadenses. Na verdade, parece que os canadenses encontram mais qualidade de vida no trabalho do que os brasileiros. Os resultados desta pesquisa mostraram claramente que esses professores fazem a diferença entre os fatores de QVT, assim como observado por Morin $(2003,2008)$ e Morin e Dassa (2004) em outros contextos pesquisados. 
Os professores canadenses têm mais autonomia no trabalho e mais oportunidades para o desenvolvimento profissional do que os professores brasileiros. Os canadenses tendem a encontrar mais retidão moral e reconhecimento do que os brasileiros. Eles também são capazes de controlar melhor suas relações emocionais no local de trabalho do que os seus colegas brasileiros. Mas os professores canadenses apontaram ter uma carga física maior de trabalho que os brasileiros. Por outro lado, os professores brasileiros tendem a sentir mais carga mental e trabalham mais horas por dia do que os canadenses.

É interessante analisar as possíveis relações entre as características da organização do trabalho, ou seja, entre as características do trabalho e das relações de trabalho. Através de correlações de Pearson, vê-se que a autonomia no trabalho está fortemente associada com o desenvolvimento profissional, o que faz sentido. $\mathrm{Na}$ verdade, o que dá autonomia para as pessoas que trabalham são: os conhecimentos e as habilidades (saber como fazer o seu trabalho), os recursos (informações sobre o trabalho a ser feito, tempo, equipamentos, etc.), o feedback sobre o desempenho (a fim de fazer os ajustes necessários) e o apoio de seu superior. Aqui, observa-se claramente que a capacidade de aprender e crescer em seu trabalho estimula a autonomia.

A autonomia também está associada com a utilidade percebida de trabalho. Quanto mais útil o trabalho é percebido, maior a autonomia, provavelmente porque estimula o interesse de fazê-lo. Finalmente, a autonomia está associada negativamente com carga emocional: quanto menos se deve "trabalhar suas emoções" para realizar o seu trabalho, maior será a autonomia. 0 que também faz sentido porque a carga emocional envolvida na realização das tarefas priva uma pessoa de sua energia útil necessária para a autoeficácia. Por se tratar de duas realidades distintas, Brasil e Canadá, um aprofundamento dos achados precisa ser entendido em termos das peculiaridades dos dois países, principalmente porque o próprio sistema educacional apresenta diferenças significativas em termos de estruturação e valorização do docente. Além disso, aspectos culturais e formas de acesso tanto de discentes quanto de docentes devem ser levados em consideração para elucidar os achados da pesquisa.

Por outro lado, existe uma relação negativa entre os fatores relacionados ao trabalho característicos de organização e cargas de trabalho. Vale a pena lembrar que a carga emocional do trabalho foi negativamente correlacionada com a autonomia. De fato, a carga de trabalho é um fator de risco psicossocial bem confirmado e atualmente a carga de trabalho dos professores universitários é muito alta devida às crescentes exigências de pesquisa e publicação, como observado por Vilas Boas e Morin (2015), Catano et al. (2010), Miller, Taylor e Bedeian (2011), Winefield et al. (2003), Vannini (2006) e Gillespie et al. (2001). Corrobora-se com o exposto por Wortman, Biernat e Lang (1991) de que os profissionais e as organizações devem buscar estratégias de enfrentamento do excesso de carga de trabalho, o que a nosso ver vai minimizar os seus efeitos negativos no sentido do trabalho.

A relação significativa positiva entre o sentido do trabalho e o sentido no trabalho de um lado, e o propósito do trabalho, autonomia, desenvolvimento profissional, retidão moral, relações com os colegas, reconhecimento e segurança no trabalho por outro lado, confirma as expectativas dos autores e corrobora com estudos anteriores (Morin, 1997; Morin 2003; Pratt \& Ashforth, 2003; Vilas Boas \& Morin, 2014, 2014a). De forma similar, observou-se uma relação negativa significativa entre o sentido do trabalho e o sentido no trabalho de um lado, e a carga física e carga emocional por outro lado, confirmando também os estudos anteriores. Entretanto, é interessante observar que a carga mental apresentou correlação positiva nesta amostra de professores universitarios, provavelmente devido à natureza do trabalho acadêmico.

\section{CONSIDERAÇÕES FINAIS}

Este inquérito foi concebido para avaliar os fatores de qualidade de vida no trabalho dos professores de universidades públicas de um país emergente como o Brasil em comparação com os de professores que trabalham em um país desenvolvido como o Canadá e relacionar esses fatores com os indicadores de sentido do trabalho. Neste estudo exploratório, os resultados mostram que, em geral, os professores sentem que têm uma boa qualidade de vida no trabalho. Professores canadenses encontram mais autonomia no trabalho e eles têm mais oportunidades de desenvolvimento profissional do que os brasileiros. Eles também percebem mais retidão moral e reconhecimento no seu trabalho do que os colegas brasileiros. No entanto, os professores universitários de Quebec sentem que têm uma carga física maior do que os professores brasileiros. Por outro lado, os professores brasileiros apontaram mais carga emocional na realização de seu trabalho do que os seus colegas canadenses e eles trabalham mais horas por 
dia também. Observou-se também que as fatores que descrevem as características do trabalho e das relações de trabalho estão todas positivamente correlacionadas com o sentido do trabalho, enquanto que as cargas de trabalho física e mental estão negativamente relacionadas com o sentido do trabalho.

Em resumo, as diferenças entre os dois grupos são pequenas e os seus efeitos de tamanho também são pequenos, exceto para o fator de autonomia no trabalho. As diferenças estão em sete fatores: autonomia, oportunidades de desenvolvimento profissional, retidão moral, reconhecimento, carga física, carga emocional e horas trabalhadas por dia. Estes resultados ajudaram a testar a aplicabilidade do modelo para avaliar os fatores de QVT em universidades públicas e para explorar a natureza da QVT em duas realidades distintas (Vilas Boas \& Morin, 2014b). De modo similar, pode-se afirmar que a melhoria da QVT no meio acadêmico está também ligada aos indicadores de QVT que não foram contemplados neste estudo, mas em outras publicações como Vilas Boas e Morin (2013b, 2013c), pois os resultados aqui apresentados fazer parte de um estudo mais amplo que contemplou indicadores, fatores e variáveis de diferenças individuais para analisar a QVT (Vilas Boas \& Morin, 2014b). No entanto, as características do trabalho, das relações de trabalho, a carga de trabalho e o sentimento de segurança no trabalho são fatores determinantes da QVT, pois proveem da própria organização do trabalho que está, de certa forma, fora do alcance do próprio professor, pois o ensino público federal respeita uma política nacional e envolve uma ampla rede de universidades cujo professor não tem, sozinho, domínio para alterar sua própria QVT. Em suma, a melhoria da QVT de professores universitários está intimamente relacionada à organização do trabalho acadêmico no contexto atual de mundialização e globalização da economia e da educação. 0 ensino universitário carece de atenção dos gestores públicos para propor melhorias consideráveis ao formato atual, que tem contribuído com a sobrecarga de trabalho dos doentes universitários e, por conseguinte, com os níveis de estresse no trabalho, afetando negativamente 0 bem-estar psicológico dos trabalhadores e o comprometimento dos mesmos com 0 trabalho e a instituição em si (Vilas Boas \& Morin, 2015).

Assim sendo, promover a qualidade de vida no trabalho é um desafio para o setor de gestão pública, mas vale a pena ser mencionado, porque todo mundo vai colher os benefícios. Tanto em termos de desempenho profissional e da qualidade dos serviços oferecidos à sociedade, bem como em termos de vida pessoal e profissional. No entanto, vale lembrar que as exigências de orientação de alunos e publicação podem ser fatores limitantes dos resultados dos efeitos da carga de trabalho sobre 0 professor, pois, atualmente, os professores universitários são tidos e avaliados mais como pesquisadores e orientadores do que professores em si.

Por se tratar de um estudo apenas quantitativo, os achados não puderam ser aprofundados de acordo com as duas realidades distintas de pesquisa. Portanto, uma descrição precisa e detalhada, através de análise documental, do sistema educacional contemplando critérios de acesso, demandas acadêmicas dos professores universitários, horário de trabalho, grau de esforço, etc. nos dois países enriqueceria os achados aqui apresentados. Por outro lado, poder-se-ia utilizar entrevistas em profundidade ou grupo focal para levantar informações mais subjetivas e pessoais que possam elucidar aspectos culturais e pessoais que afetam no desempenho docente e na sua relação com a instituição de ensino e sua própria vida pessoal. Aspectos estes que estão diretamente relacionados ao construto sentido do trabalho e aos demais indicadores de qualidade de vida no trabalho.

Para novos estudos sobre QVT no setor público, sugere a realização de pesquisas similares em outros setores e em outras universidades. Na prática sugere-se enfatizar a utilidade social do trabalho, oferecer mais autonomia para os profissionais, oferecer oportunidades de exercer julgamento, aplicar a inteligência e a criatividade, proporcionar aprendizagem e oportunidades de desenvolvimento, reforçar a retidão moral através do desenvolvimento do bem-estar e da consciência moral, e mostrar mais consideração pela dignidade humana. Adicionalmente, poder-se-á trabalhar com indicadores de capacidade para o trabalho, grau de esforço físico e mental e vocação para a atividade docente em prol da melhoria da Qualidade de Vida no Trabalho de professores universitários tanto em países desenvolvidos quanto países em desenvolvimento.

\section{AGRADECIMENTOS}

Os autores agradecem à CAPES pelo financiamento desta pesquisa. 


\section{REFERÊNCIAS}

BOISVERT, M. P. The quality of working life: an analysis. Human Relations, v. 30, n. 2, p. 155-160, 1977.

CATANO, V.; FRANCIS, L.; HAINES, T.; KIRPALANI, H.; SHANNON, H.; STRINGER, B.; LOZANZKI, L. Occupational Stress in Canadian Universities: a national survey. International Journal of Stress Management, v. 17, n. 3, p. 232-258, 2010.

CHENG, G. H. L.; CHAN, D. K. S. Who suffers more from job insecurity? A meta-analytic review. Applied Psychology, v. 57, n. 2, p. 272-303, 2008. DOI: 10.1111/j.1464-0597.2007.00312.x

CONSTANTINO, M. A. C. Avaliação da Qualidade de Vida: desenvolvimento e validação de um instrumento, por meio de indicadores biopsicossociais, junto à comunidade da Universidade de São Paulo-USP. Dissertação (Mestrado em Administração) - Universidade de São Paulo, Faculdade de Economia e Administração - FEA, Programa de Pós-Graduação em Administração, São Paulo, 2007.

DAVIS, L. E.; CHERNS, A. B. (Eds). The Quality of Working Life. (V. 1. Problems, Prospects, and the State of the Art), New York, USA, Free Press, 1975.

DEBUS, M. E.; PROBST, T. M.; KÖNIG, C. J.; KLEINMANN, M. Catch Me If I Fall! Enacted Uncertainty Avoidance and the Social Safety Net as Country-Level Moderators in the Job Insecurity-Job Attitudes Link. Journal of Applied Psychology. Advance online publication, v. 97, p. 690-698, 2012. DOI: 10.1037/a0027832.

DE CUYPER, N.; NOTELAERS, G.; DE WITTE, H. Job Insecurity and Employability in Fixed-Term Contractors, Agency Workers, and Permanent Workers: Associations with Job Satisfaction and Affective Organizational Commitment. Journal of Occupational Health Psychology, v. 14, n. 2, p.193-205, 2009. DOI: 10.1037/a0014603

DE OLIVEIRA, P. M.; LIMONGI-FRANÇA, A. C. Avaliação da gestão de programas de qualidade de vida no trabalho. RAE-eletrônica, v. 4, n.1, p. , 2005.

DE WITTE, H. Job insecurity and psychological well-being: Review of the literature and exploration of some unresolved issues. European Journal of Work and Organizational Psychology, n. 8, p. 155-177, 1999. DOI: 10.1080/135943299398302

GILLESPIE, N. A.; WALSH, M.; WINEFIELDS, A. H.; DUA, J.; STOUGH C. Occupational Stress in Universities: staff perceptions of the causes, consequences and moderators of stress. Work \& Stress. v. 15, n. 1, p. 53-72, 2001.

GRECH, M. R.; NEAL, A.; YEO, G.; HUMPHREYS, M.; SMITH, S. An Examination of the Relationship Between Workload and Fatigue Within and Across Consecutive Days of Work: Is the Relationship Static or Dynamic? Journal of Occupational Health Psychology. v. 14, n. 3, p. 231-242, 2009.

GROPHER, D.; DONCHIN, E. Workload: An examination of the concept. In: BOFF, K.; KAUFMAN, L.; THOMAS, J. P. (Eds). Handbook of Perception and Human Performance. Wiley, New York. 41, p. 1-27, 1986.

HANCOCK, P. A.; VERWEY, W. B. Fatigue, workload and adaptive driver systems. Accident Analysis and Prevention, v. 29, n. 4, p. 495-506, 1997.

HANCOCK, P. A.; RODENBERG, G. J.; MATHEWS, W.; VERCRUYSSEN, M. Estimation of duration and mental workload at different times of the day by males and females. Proc Human Factors Soc., 32, p. 857-861, 1988.

HART, S. G.; STAVELAND, L. E. Development of NASA-TLX (task Load Index): Results of empirical and theoretical research. In: P. A. Hancock and N. Meshkati (eds). Human Mental Workload. North-Holland, Ansterdam, p. 139-183, 1988.

ILMARINEN, J.; TUOMI, K.; SEITSAMO J. New dimensions of work ability. In: COSTA, G.; GOEDHARD W. J. A.; ILMARINEN, J. (EdS). ITERNATIONAL SYMPOSIUM IN WORK ABILITY: ASSESSMENT AND PROMOTION OF WORK ABILITY, HEALTH AND WELL-BEING OF AGEING WORKERS. $2^{\text {nd }}, 2005$, London. Proceedings of the ..., London: Elsevier; 2005. p. 3-7. 
KANTOWITZ, B. H. Mental workload. In: P. A. Hancock (Ed.) Human factors psychology. North-Holland, Amsterdam, p. 81-121, 1987.

KERTESZ, R.; KERMAN, B. El Manejo del Stress. Buenos Aires: IPPEM, 1985, 442p.

KETCHUM, L. D.; TRIST, E. All teams are not created equal: how employee empowerment really works. Newbury Park: Sage, 1992.

KINMAN. G.; JONES, F. A Life Beyond Work? Job Demands, Work-Life Balance, and Wellbeing in UK Academics. Journal of Human Behavior in the Social Environment, v. 17, n. 1-2, p. 41-60, 2008. DOI: 10.1080/10911350802165478

ROSCH, J. P. Exclusive Interview with Lennart Levi MD, PhD on Occupational Stress. Health and Stress, v. 24, n 10, Special Issue, p. 1-22 October 2012.

LEVINE, M. F. Self-developed QWL measures. Journal of Occupational Behavior, v. 4, n.1, p. 35-46, 1983.

LIMONGI-FRANÇA, A. C. Qualidade de vida no trabalho: conceitos e práticas nas empresas da sociedade pósindustrial. Atlas, 2003.

LORI, F.; BARLING, J. Organizational Injustice and Psychological Strain. Canadian Journal of Behavioral Science, v. 37, n. 54, p. 250-261, 2005.

MARTINEZ, M. C.; LATORRE, M. do R. D. de; FISCHER, F. M. Capacidade para o Trabalho: revisão de literatura. Ciência \& Saúde Coletiva, v. 15, n. 1, p. 1553-1561, 2010. DOI: 10.1590/S1413-812320100000700067

MATTHEWS, G.; DESMOND, P. A. Task-induced fatigue states and simulated driving performance. The Quarterly Journal of Experimental Psychology, v. 55, n. 2, p. 659-686, 2002.

MATTHEWS, G.; CAMPBELL, S. E.; FALCONER, S.; JOYNER, L. A.; HUGGINS, J.; GILLILAND, K. Fundamental dimensions of subjective state in performance settings: Task engagement, distress and worry. Emotion, v. 2, p. 315340, 2002.

MILLER, A. N. TAYLOR, S. G.; BEDEIAN, A. G. Publish or Perish: Academic life as management faculty live it. The Career Development International, v. 16, n. 5, p. 422-425, 2011. DOI: 10.1108/13620431111167751

MORIN, E. M. Le sens du travail pour des gestionnaires francophones. Psychologie du travail et des organisations, v. 2, n. 3, p. 26-45, 1997.

MORIN, E. M. Os sentidos do trabalho. Revista de Administração de Empresas, v. 41, n. 3, p. 8-19, 2001.

MORIN E. M. Sens du travail. Définition, mesure et validation. In: VANDENBERGHE, C.; DELOBBE, N.; KARNAS, G. (éds), Dimensions individuelles et sociales de l'investissement professionnel. Actes du XIIE CONGRES DE PSYCHOLOGIE DU TRAVAIL ET DES ORGANISATIONS. Louvain-la-Neuve, UCL Presses universitaires de Louvain, v. 2, p. 11-20, 2003.

MORIN, E. M. Sens du travail, santé mentale au travail et engagement organisationnel, Études et recherches, (Rapport R-543 - avec la collaboration de F. Aranha, FGV-EASP), Montreal, QC, Canada, IRSST, 2008, 62p.

MORIN E. M.; CHERRÉ B. Les cadres face au sens du travail. Revue Française de Gestion, v. 126, p. 83-93, 1999.

MORIN, E. M.; DASSA, C. Characteristics of a meaningful work: Construction and validation of a scale. HEC Montréal/Université de Montréal, Montréal, QC, Canada, 2004.

O'DONNELL, R. D.; EGGEMEIER, T. Workload assessment methodology. In: BOFF, K. R.; KAUFMAN, L.; THOMAS, L. P. (Eds.) Handbook of Perception and Human Performance. Wiley, New York, v. 42, p. 28-49, 1986. DOI: 10.1037/a0027832.

ROSCH, J. P. Exclusive Interview with Lennart Levi MD, PhD on Occupational Stress. Health and Stress, v. 24, n 10, Special Issue, p. 1-22, October 2012. 
ROYUELA, V.; LOPEZ-TAMAYO, J.; SURINACH, J. The institutional vs. the academic definition of the quality of work life: What is the focus of the European Commission? Social Indicators Research. v. 86, v. 3, p. 401-415, 2008.

SAMPAIO, J. dos R. Qualidade de vida no trabalho: perspectivas e desafios atuais. Revista Psicologia Organizações e Trabalho, v. 12, n.1, p. 121-136, 2012.

SANT'ANNA, A. de S.; KILIMNIK, Z. M. Qualidade de vida no trabalho: abordagens e fundamentos. Rio de Janeiro: Campus-Elsevier (2011).

SVERKE, M.; HELLGREN, J.; NÄSWALL, K. No security: A meta-analysis and review of job insecurity and its consequences. Journal of Occupational Health Psychology, v. 7, n. 3, p. 242-264, 2002. DOI: 10.1037/10768998.7.3.242

TOLFO, S. da R.; PICCININI, V. C. Sentidos e significados do trabalho: explorando conceitos, variáveis e estudos empíricos brasileiros. Psicologia \& Sociedade, v.19, ed. esp. n, 1, p. 38-46, 2007.

VAN VUUREN, C. V.; KLANDERMANS, P. G. Individual reactions to job insecurity: An integrated model. In: P. J. D. DRENTH, P. J. D.; SERGEANT, J. A.; TAKENS, R. J. (Eds.), European perspectives in psychology, Chichester, England: Wiley, v. 3, p. 133-146, 1990.

VANNINI, P. Dead Poets' Society: Teaching, Publish-or-Perish and Professors' Experience of Authenticity. Symbolic Interaction, v. 29, n. 2, p. 235-257, 2006. DOI: 10.1525/si.2006.29.2.235

VIDULICH, M. A.; TSANG, P. S. Techniques of subjective workload assessment: a comparison of SWAT and the NASA-Bipolar methods. Ergonomics, v. 29, p. 1385-1398, 1986.

VILAS BOAS, A. A.; MORIN, E. M. Le sens du travail et la qualité de vie au travail dans les établissements publics d'enseignement supérieur: une comparaison entre le Brésil et le Canada. LA COLLOQUE INTERNATIONAL AFIRSE: RECHERCHE EN ÉDUCATION : CONTINUITÉ, RUPTURE OU LIMITES? 2013, UQAM, Montréal, QC, Canadá. Poursuites de, Montréal, CA : AFIRSE, Maio 2013.

VILAS BOAS, A. A.; MORIN, E. M. El sentido del trabajo y la calidad de vida en el trabajo dentro de los establecimientos públicos de enseñanza superior: una comparación entre Brasil y Canadá. Boletin Informativo, Ciudad de Quatemala: Ministerio de Relaciones Exteriores - El Heraldo Diplomático - Biblioteca Mario Monteforte Toledo, v. 56, Jul. 2013a.

VILAS BOAS, A. A.; MORIN, E. M. Indicadores de qualidade de vida no trabalho para instituições públicas de ensino superior: uma comparação entre Brasil e Canadá. ENCONTRO NACIONAL DA ASSOCIAÇÃO NACIONAL DE PÓSGRADUAÇÃO E PESQUISA EM ADMINISTRAÇÃO, 37, Set. 2013, Rio de Janeiro. Anais ... Rio de Janeiro, ANPAD, 2013b.

VILAS BOAS, A. A.; MORIN, E. M. Quality of Working Life in Public Higher Education Institutions: the perception of Brazilian and Canadian professors. International Journal of Business and Social Science, v.4, n. 12, Special Issue, p. 67-77, Set, 2013c.

VILAS BOAS, A. A.; MORIN, E. M. Fatores de Qualidade de Vida no Trabalho em Universidades Públicas: Uma Comparação entre Brasil e Canadá. CONGRESSO DE STRESS DA ISMA (INTERNACIONAL STRESS MANAGEMENT ASSSOCIATION) e FÓRUM DE QUALIDADE DE VIDA NO TRABALHO, $14^{\circ}$ e $16^{\circ}$, Jun. 2014, Porto Alegre. Anais ... Porto Alegre, ISMA, 2014.

VILAS BOAS, A. A.; MORIN, E. M. Sentido do Trabalho e Fatores de Qualidade de Vida no Trabalho para Professores de Universidades Públicas do Brasil e do Canadá. ENCONTRO NACIONAL DA ASSOCIAÇÃO NACIONAL DE PÓS-GRADUAÇÃO E PESQUISA EM ADMINISTRAÇÃO, 38, Set. 2014, Rio de Janeiro. Anais ... Rio de Janeiro, ANPAD, 2014a.

VILAS BOAS, A. A.; MORIN, E. M. La Qualité de Vie au Travail des professeurs des établissements publics d'enseignement supérieur: une comparaison entre le Brésil et le Canada. Rapport de Recherche de post-doctorale, HEC, Montreal, Canadá, 2014b. 119 p. 
VILAS BOAS, A. A.; MORIN, E. M. Stress no Trabalho, Bem-Estar Psicológico e Comprometimento com o Trabalho: Efeitos e Relações com a Qualidade de Vida no Trabalho. In: ROSSI, A. M.; MEURS, J. A.; PERREWÉ, P. L. (Orgs.). Stress e qualidade de vida no trabalho: Stress Interpessoal e Ocupacional. São Paulo: Atlas, 2015. p. 119-140.

VIRTANEN, P.; VAHTERA, J.; NAKARI, R.; PENTII, J.; KIVIMAÄKI, M. Economy and job contract as contexts of sickness absence practices: Revisiting locality and habitus. Social Science \& Medicine, v. 58, n. 7, p. 1219-1229, April 2004.

WINEFIELD, A. H.; GILLESPIE. N.; SLOUGH, C.; DUA. J.; HAPUARACHCHI, J.; BOYD, C. Occupational stress in Australian University Staff. International Journal of Stress Management, v. 10, n. 1, p. 51-63, 2003.

WORTMAN, C.; BIERNAT, M.; LANG. E. Coping with role overload. In: FRANKENHAEUSER, M.; LUNDBERG, U.; CHESNEY, M. (Eds.) Women, Work and Health: Stress and Opportunities, London: Plenum, 1991.

ZOHAR, D.; TZISCHINSKI, O.; EPSTEIN, R. Effects of energy availability on immediate and delayed emotional reactions to work events. Journal of Applied Psychology, v. 88, n. 6, p. 1082-1093, 2003.

i A primeira versão deste artigo, mais resumida, foi apresentada no ENANPAD 2014. 